\title{
Efficacy of Low Dose Doxorubicin Therapy in Patients with Non-APL Acute Myeloblastic Leukemia
}

\section{Khaled SAA*}

Department of Internal Medicine, Clinical Hematology Unit, Assiut University Hospital, Faculty of Medicine, Assiut University, Egypt

\begin{abstract}
Background: Doxorubicin is a chemotherapeutic drug that acts by blocking topoisomerase 2 enzyme. It is used for treatment of many solid and hematological cancers; unfortunately it has serious side effects. The usual Doxorubicin dose for patients with acute myeloblastic leukemia (AML) is $40-60 \mathrm{mg} / \mathrm{m}^{2}$. This is the first study that assessed the efficacy of low dose Doxorubicin in patients with non acute promyelocytic leukemia (APL) AML.

Methods: A retrospective study was done at Assiut University, where data were collected from hospital records of 103 patients with AML, after fulfilling certain inclusion criteria. Patients were treated with the conventional 3/7 induction regimen, however doxorubicin was prescribed in a lower dose compared with other studies.

Results: The median age of our patients was 38 years, and $86.4 \%$ were with primary AML. Complete remission (CR) was achieved in $60.2 \%$ of the study patients. Primary AML type and M2 FAB subtype, were found to be good prognostic factors $(P=0.000$ and 0.067 , respectively). Survival analysis showed that the longest overall survival (OS) and disease free survival (DFS) for the study patients were 60 and 55 months respectively. There was no significant difference regarding OS and DFS between male and female patients ( $P=0.903,0.848$, respectively).

Conclusion: In conclusion this study provided a novel therapeutic strategy that encourages the use of low dose Doxorubicin for treatment of young age adults with non- APL AML. This will reduce treatment expenses, minimize cardiotoxicity, and allow addition of adjunctive therapy which in its turn minimizes resistance.
\end{abstract}

Keywords: Doxorubicin; Acute myeloblastic leukemia; Efficacy

\section{Introduction}

Acute myeloblastic leukemia is a blood cancer in which the bone marrow is flooded with malignant cells of myeloid lineage; these cells interfere with the growth of normal blood cells resulting in variable degrees of cytopenias [1-3] although a lot of research was conducted to develop effective targeted therapy for AML, yet the conventional 3/7 induction protocol still the gold standard for treatment of patients with AML [4-6].

Doxorubicin is a cell cycle specific anti-neoplastic drug that belonged to the anthracycline antibiotic group. Doxorubicin is used in the 3/7 induction regimen in AML, it is also used as a chemotherapy for a wide array of malignancies [7-9]. Unfortunately it can cause serious affection of the myocardium and progressive reduction of ejection fraction. This effect is mainly cumulative and could occur even 8- years after stoppage of the drug. Another serious complication of Doxorubicin is the development of secondary leukemia [10-12].

Doxorubicin is relatively the cheapest and most available anthracycline, however it is not commonly used compared to Daunorubicin and Idarorubicin. The most commonly used dose range of Doxorubicn for AML patients is $40-60 \mathrm{mg} / \mathrm{m}^{2}$ [13-16].

\section{Materials and Methods}

\section{Study objectives}

This study aimed to assess the efficacy of low dose doxorubicin therapy in patients with non- APL AML.

\section{Significance of the study}

We assumed that this is the first study that assessed efficacy of low dose $\left(25 \mathrm{mg} / \mathrm{m}^{2}\right)$ Doxorubicin in $3 / 7$ induction regimen of patients with non-APL AML

\section{Study settings and design}

The study was done at the Medical Oncology Department at South Egypt Cancer Institute (SECI) and the Clinical Hematology Unit at Internal Medicine Department, Assiut University Hospital (AUH). The design was retrospective that was based on hospital records of AML patients who were admitted and treated at the above mentioned Departments in the period Jan 2009- to Dec 2013. During these periods AML patients were treated with low dose Doxorubicin during induction phase of chemotherapy. Although this regimen is not commonly used, we use it in our patients due to many reasons. The most important were the cheaper price and wider availability of Doxorubicin compared to Idarubicin and Daunorubicin. Furthermore the common associated co-morbidities, low Eastern Co-operative group (ECOG) performance status of our patients and ineffective supportive measures, all of these enforced us to use lower dose Doxorubicin rather than the commonly used ones. Another important point was to reduce the possible

*Corresponding author: Khaled SAA, Department of Internal Medicine, Clinica Hematology Unit, Assiut University Hospital, Faculty of Medicine/Unit of Bone Marrow Transplantation, South Egypt Cancer Institute, Assiut University, Egypt, Tel: +201064170058; E-mail: safaakhaled2003@gmail.com

Received November 10, 2019; Accepted November 18, 2019; Published November 22, 2019

Citation: Khaled SAA (2019) Efficacy of Low Dose Doxorubicin Therapy in Patients with Non-APL Acute Myeloblastic Leukemia. J Blood Lymph 9: 253.

Copyright: ( 2019 Khaled SAA. This is an open-access article distributed under the terms of the Creative Commons Attribution License, which permits unrestricted use, distribution, and reproduction in any medium, provided the original author and source are credited. 
Citation: Khaled SAA (2019) Efficacy of Low Dose Doxorubicin Therapy in Patients with Non-APL Acute Myeloblastic Leukemia. J Blood Lymph 9: 253.

incidence of cardiotoxicity when using higher doses of Doxorubicin.

\section{Study patients}

The study included AML patients who admitted and treated in the previously mentioned time and settings.

Exclusion criteria:

- Patients aged $>50$ years.

- Patients with M3 FAB subtype

- Patients with relapsed AML

- Patients who received therapy other than Doxorubicin such as elderly patients and those who reached the higher cumulative dose of Doxorubicin or any other anthracycline.

- Patients with incomplete hospital records

\section{Methods of data collection}

In the current study, data were collected from patients' files and hospital records, after exclusion of patients who were unsuitable for the study. Hospital records of the selected patients were thoroughly arranged and reviewed for data collection. The collected data were categorized into demographic, clinical data at presentation, hematologic parameters, French- American- British (FAB) subtype of AML, and therapeutic response. A follow up was tediously done for each patient from the date of admission to the date of death or last follow up, or relapse, or development of complications. This was mainly to estimate the overall survival (OS) and disease free survival (DFS) for each patient. During the time of the study cytogenetic and immunophenotypic analyses were not routinely done for all AML patients in our centers, accordingly these data were not available for all patients of the study, hence it was omitted.

\section{Important definitions}

The World Health Organization (WHO) criteria for AML diagnosis were applied to our patients [17]. Patients received 3/7 induction regimen in the form of Doxorubicin $25 \mathrm{mg} / \mathrm{m}^{2} /$ day for three days and cytarabine $100 \mathrm{mg} / \mathrm{m}^{2} /$ day for seven days by continuous intravenous infusion [8]. The International Working Group definition of CR was used to assess therapeutic response [17]. Accordingly CR was defined clinically by independence from RBCs transfusion and absence of any extramedullary affection, and by a peripheral hemogram that showed platelet count $>100.000 /$ ul and a neutrophil count $>1000 /$ ul . Another important criterion was absence of Auer rods and presence of $<5 \%$ blast on bone marrow examination. Patients who showed suboptimal response received another cycle of induction regimen, then reassessed again, if suboptimal response persisted patients were subjected to $3^{\text {rd }}$ cycle of induction and re-evaluation. Those who developed complications of the treatment or the disease were managed accordingly and their therapeutic response was included in the category of complications.

OS for patients was estimated from the first day of therapy to death. DFS for those who achieved CR was calculated from the date of CR to relapse or death.

\section{Statistical analyses}

Data were collected, coded and analyzed with SPSS V. 17.0, Inc, Chicago, USA, software for windows. Descriptive statistics of numerical variables were expressed as mean $\pm \mathrm{SD}$, median, minimum, maximum and range, while those of categorical variables were presented as percentages. Influence of gender, FAB subtypes, and AML type and other categorical variables on response to treatment was assessed with the Chi- square test. Spearman's Rank correlation coefficient was used to assess the association between quantitative variables and therapeutic response. Survival analysis was done using Kaplan-Meier survival analysis. Significance was considered when $\mathrm{P}$ value $<0.05$.

\section{Ethical considerations}

The study protocol and methods were in accordance with the declaration of Helsinki. Also the study design and methods were discussed and approved from the head and members of the Departments where the study was done, then was approved by the ethical committee of the postgraduate and research affairs at Faculty of Medicine, Assiut University. All of this was done before handling patients' records. Data were introduced into a personal computer and confidentiality was addressed.

\section{Results}

\section{Characteristics of the study patients}

Table 1 showed characteristics of the study patients. 103 patients

\begin{tabular}{|c|c|}
\hline Variable & Non-APL AML patients $(n=103)$ \\
\hline \multicolumn{2}{|c|}{ Gender } \\
\hline Male & $57(55.3 \%)$ \\
\hline Female & $46(44.7 \%)$ \\
\hline \multicolumn{2}{|l|}{ Governorate } \\
\hline Assiut & $65(63.1 \%)$ \\
\hline Below Assiut & $20(19.4 \%)$ \\
\hline Above Assiut & $18(17.5)$ \\
\hline \multicolumn{2}{|c|}{ Social environment } \\
\hline Urban & $53(51.5 \%)$ \\
\hline Rural & $50(48.5 \%)$ \\
\hline \multicolumn{2}{|l|}{ Occupation } \\
\hline Housewife & $33(32 \%)$ \\
\hline Employed & $25(24.3 \%)$ \\
\hline Farmer & $24(23.3 \%)$ \\
\hline Unemployed & $21(20.4 \%)$ \\
\hline \multicolumn{2}{|c|}{ Clinical characteristics symptoms } \\
\hline Symptoms of cytopenias & $73(70.9 \%)$ \\
\hline Symptoms of cytopenias and bone pains & $21(20.4 \%)$ \\
\hline Symptoms of cytopenias and others & $3(2.9 \%)$ \\
\hline $\begin{array}{l}\text { Symptoms of cytopenias, bone pains and } \\
\text { others }\end{array}$ & $6(5.9 \%)$ \\
\hline \multicolumn{2}{|l|}{ Signs } \\
\hline Signs of cytopenias & $67(65 \%)$ \\
\hline Signs of cytopenias and HSM & $24(23.3 \%)$ \\
\hline Signs of cytopenias and lymphadenopathy & $7(6.8 \%)$ \\
\hline $\begin{array}{l}\text { Signs of cytopenias, HSM and } \\
\text { Lymphadenopathy }\end{array}$ & $5(4.9 \%)$ \\
\hline \multicolumn{2}{|c|}{ Type of AML } \\
\hline De novo & $89(86.4 \%)$ \\
\hline Secondary & $14(13.6 \%)$ \\
\hline \multicolumn{2}{|c|}{ Preleukemic disorder } \\
\hline No & $89(86.4 \%)$ \\
\hline CML & $13(12.6 \%)$ \\
\hline Myelofiberosis & $1(1 \%)$ \\
\hline
\end{tabular}

Table 1: Characteristics of non-APL acute myeloblastic leukemia patients included in the study.

N.B. APL: Acute Promyelocytic Leukemia, HSM: Hepatosplenomegaly, CML: Chronic Myeloid Leukemia. 
Citation: Khaled SAA (2019) Efficacy of Low Dose Doxorubicin Therapy in Patients with Non-APL Acute Myeloblastic Leukemia. J Blood Lymph 9: 253.

were enrolled in the study, their median age was 38-years, and the age range was $17-50$ years. $55.3 \%$ of patients were males, and the male to female ratio was, $1.2: 1.63 .1 \%$ of patients were from Assiut, $51.5 \%$ were from Urban areas. Most of the patients were farmers and unemployed (23.3\% and $24.3 \%$, respectively).

More than two thirds of patients were presented with manifestations of cytopenias. Secondary AML comprised only $13.6 \%$ of patients and chronic myeloid leukemia was the commonest pre-leukemic disorder.

Table 2, showed hematologic parameters of the study patients, in this study the median blast $\%$ was $55 \%$. FAB subtypes of the study patients were in order of frequency FAB M2, followed by FAB M4, M1, M5, M6, M7, and lastly M1-2 (29.1\% and $25.2 \%, 17.5 \%, 12.6 \%$, $10.7 \%, 3.9 \%$, and $1 \%$ respectively), as in Figure 1. Figure 2 showed distribution of the study patients over years of the study, it revealed that considerable percentage of patients were admitted during years 2011 and 2010.

\section{Response to low dose doxorubicin therapy and fate of the study patients}

$60.2 \%$ of patients showed CR, from these $36.9 \%, 17.5 \%$, and $5.8 \%$ showed remission after first, second and third induction respectively. A considerable proportion of our patients developed complications $21.4 \%$, as in Table 3 . It is obvious that the maximum cumulative dose of Doxorubicin in our patients was $75 \mathrm{mg} / \mathrm{m}^{2}$.

Table 3, showed that nearly one third of our patients $(29.1 \%)$ stopped treatment, $10.7 \%$ relapsed and $17.7 \%$ died over years of the study. $28.2 \%$ of our patients stayed in remission. In $14.4 \%$ of the study sample the fate of the patients was not available in their records.

\section{Factors that affect response to treatment in the study patients}

Table 4 showed prognostic impact of both patient and disease related factors, it revealed insignificant effect of gender on therapeutic response $(\mathrm{P}=0.47)$, the same was found with $\mathrm{FAB}$ subtypes. On the contrary a significant good prognostic impact was noted for AML type where $100 \%$ of patients who show remission after $1^{\text {st }}$ induction were with de novo AML. Furthermore, $57.1 \%$ and $35.7 \%$ of those with secondary AML were either complicated or did not show remission.

The association between quantitative variables and therapeutic response was also assessed and showed a significant association

\begin{tabular}{|c|c|c|c|c|c|c|c|c|c|c|}
\hline & \multirow{2}{*}{$\begin{array}{c}\text { Minimum } \\
\text { Statistic }\end{array}$} & \multirow{2}{*}{$\begin{array}{c}\text { Maximum } \\
\text { Statistic }\end{array}$} & \multicolumn{2}{|c|}{ Mean } & \multirow{2}{*}{$\begin{array}{c}\text { SD } \\
\text { Statistic }\end{array}$} & \multicolumn{2}{|c|}{ Skewness } & \multicolumn{3}{|c|}{ Median } \\
\hline & & & Statistic & Std. Error & & Statistic & Std. Error & Statistic & $\mathbf{R}$ & P-value \\
\hline TLC & 1.0 & 84.0 & 16.35 & 2.16 & 21.92 & 1.60 & 0.23 & 3.5 & $0.340^{* *}$ & 0.000 \\
\hline $\mathrm{Hb}$ & 3.0 & 14.4 & 7.02 & 0.20 & 2.09 & 0.36 & 0.23 & 7 & -0.148 & 0.136 \\
\hline Plts & 5 & 450 & 103.33 & 9.11 & 92.54 & 1.69 & 0.23 & 75 & 0.087 & 0.384 \\
\hline Blast $\%$ & 22 & 100 & 58.57 & 2.41 & 24.51 & 0.21 & 0.23 & 55 & -0.073 & 0.468 \\
\hline Age & 17 & 50 & 34.70 & & 11.53 & & & 38 & $0.524^{* *}$ & 0.000 \\
\hline
\end{tabular}

Table 2: Age and hematologic parameters of non-APL acute myeloblastic leukemia patients included in the study and their effect on the therapeutic response to Doxorubicin $(\mathrm{n}=103)$. N.B. TLC $\left(x 1,000 / \mathrm{mm}^{3}\right)=$ Total Leucocytic Count, Hb=Hemoglobin $(\mathrm{g} / \mathrm{dl})$, Plts=Platelets $\left(x 1,000 / \mathrm{mm}^{3}\right)$. ${ }^{* \star *}$ Correlation is significant at the 0.01 level $(2$-tailed).

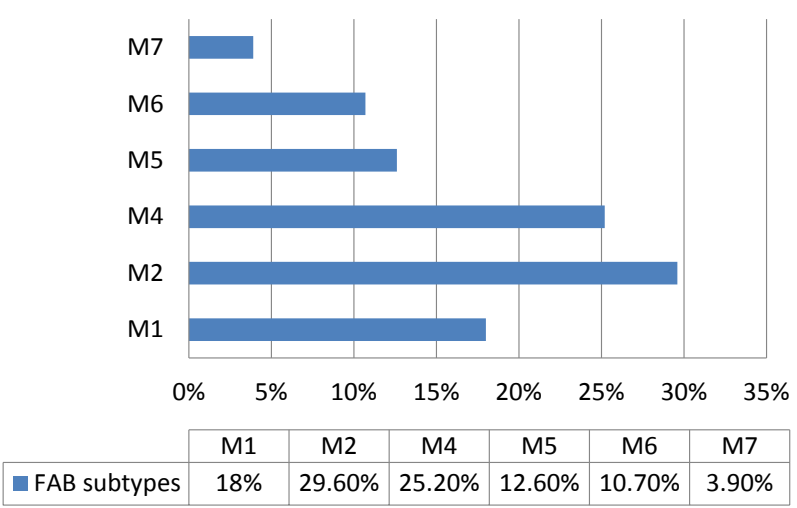

Figure 1: French-American-British (FAB) subtypes of non-APL acute myeloblastic leukemia patients included in the study ( $n=103)$.

Year of the study

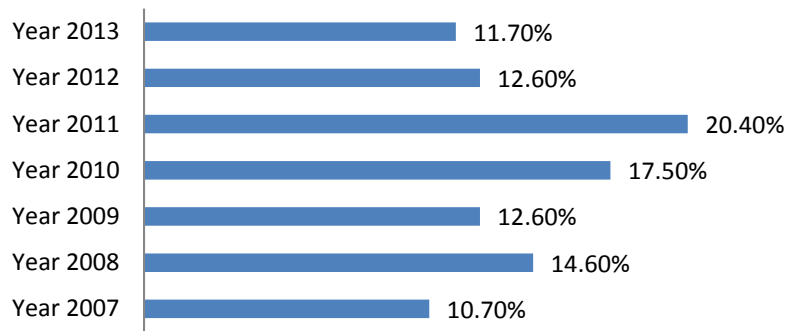

Figure 2: Distribution of non-APL acute myeloblastic leukemia patients over years of the study (from 2007 to 2013). 
Citation: Khaled SAA (2019) Efficacy of Low Dose Doxorubicin Therapy in Patients with Non-APL Acute Myeloblastic Leukemia. J Blood Lymph 9: 253.

between age, TLC and therapeutic response, as in Table 2, however effect of other parameters was insignificant.

In Figure 3 it was clear that the best therapeutic response was obtained during the last 3-years of the study where many patients remit after $1^{\text {st }}$ induction.

\section{Survival analysis of the study patients}

Kaplan Meier analysis of survival was used to assess OS and DFS of the study patients it showed no statistically significant differences in survival among male and female patients. The Mean OS was $28.9 \pm 2.8$ and $29.1 \pm 7.6$, and the mean DFS was $27.7 \pm 2.6$ and $29.5 \pm 7.7$ for male

\begin{tabular}{|c|c|c|c|}
\hline Response & Frequency & Percent & Cumulative Percent \\
\hline Not in remission & 19 & 18.4 & 18.4 \\
\hline Complications & 22 & 21.4 & 39.8 \\
\hline Remision after $1^{\text {st }}$ induction & 38 & 36.9 & 76.7 \\
\hline Remision after $2^{\text {nd }}$ induction & 18 & 17.5 & 94.2 \\
\hline Remission after $3^{\text {rd }}$ induction & 6 & 5.8 & 100.0 \\
\hline Fate-Relapse & 11 & 10.7 & 10.7 \\
\hline No relapse & 29 & 28.2 & 38.8 \\
\hline Cessation of ttt & 30 & 29.1 & 68.0 \\
\hline Death & 18 & 17.7 & 78.6 \\
\hline Unknown & 15 & 14.4 & 100.0 \\
\hline Total & 103 & 100.0 & \\
\hline
\end{tabular}

Table 3: Response to treatment and fate of Non-APL acute myeloblastic leukemia patients $(n=103)$.

\begin{tabular}{|c|c|c|c|c|c|c|}
\hline Variable & $\begin{array}{l}\text { Remision after } 1^{\text {st }} \\
\text { induction }\end{array}$ & Not in remission & Complications & $\begin{array}{l}\text { Remision after } 2^{\text {nd }} \\
\text { induction }\end{array}$ & $\begin{array}{c}\text { Remission after } 3^{\text {rd }} \\
\text { induction }\end{array}$ & P-value \\
\hline \multicolumn{7}{|c|}{ Gender } \\
\hline Male & $23(60.5 \%)$ & $12(63.2 \%)$ & $11(50.0 \%)$ & $8(44.4 \%)$ & $3(50 \%)$ & 0.72 \\
\hline Female & $3(50 \%)$ & $7(36.8 \%)$ & $11(50 \%)$ & $10(55.6 \%)$ & $3(50 \%)$ & \\
\hline \multicolumn{7}{|c|}{ FAB } \\
\hline M1 & $8(21.1 \%$ & $4(21.1 \%)$ & $4(8.2 \%)$ & $2(11.1 \%)$ & $0(0 \%)$ & \\
\hline M2 & $13(34.25)$ & $3(13.8 \%)$ & $6(27.3 \%)$ & $7(38.9 \%)$ & $2(33.3 \%)$ & \\
\hline M4 & $7(18.4 \%)$ & $8(42.1 \%)$ & $5(22.1 \%)$ & $5(27.8 \%)$ & $1(16.7 \%)$ & 0.77 \\
\hline M5 & $6(15.8 \%)$ & $2(10.5 \%)$ & $2(9.1 \%)$ & $2(11.1 \%)$ & $1(16.7 \%)$ & \\
\hline M6 & $3(7.9 \%$ & $2(10.5 \%)$ & $3(13.6 \%)$ & $1(5.6 \%)$ & $2(33.3 \%)$ & \\
\hline M7 & $1(2.6 \%)$ & $0(0 \%)$ & $2(9.1 \%)$ & $1(5.6 \%)$ & $0(0 \%)$ & \\
\hline \multicolumn{7}{|c|}{ AML type } \\
\hline De novo & $38(100 \%)$ & $15(78.9 \%)$ & $15(68.2 \%)$ & $15(83.3 \%)$ & $6(100 \%)$ & $0.007^{* *}$ \\
\hline Secondary & $0(0 \%)$ & $4(21.1 \%)$ & $7(31.8 \%)$ & $3(16.7 \%)$ & $0(0 \%)$ & \\
\hline
\end{tabular}

Table 4: X2 test results of the association between qualitative variables and response to low dose Doxorubicin therapy in patients with non-APL acute myeloblastic leukemia.

\section{Bar Chart}

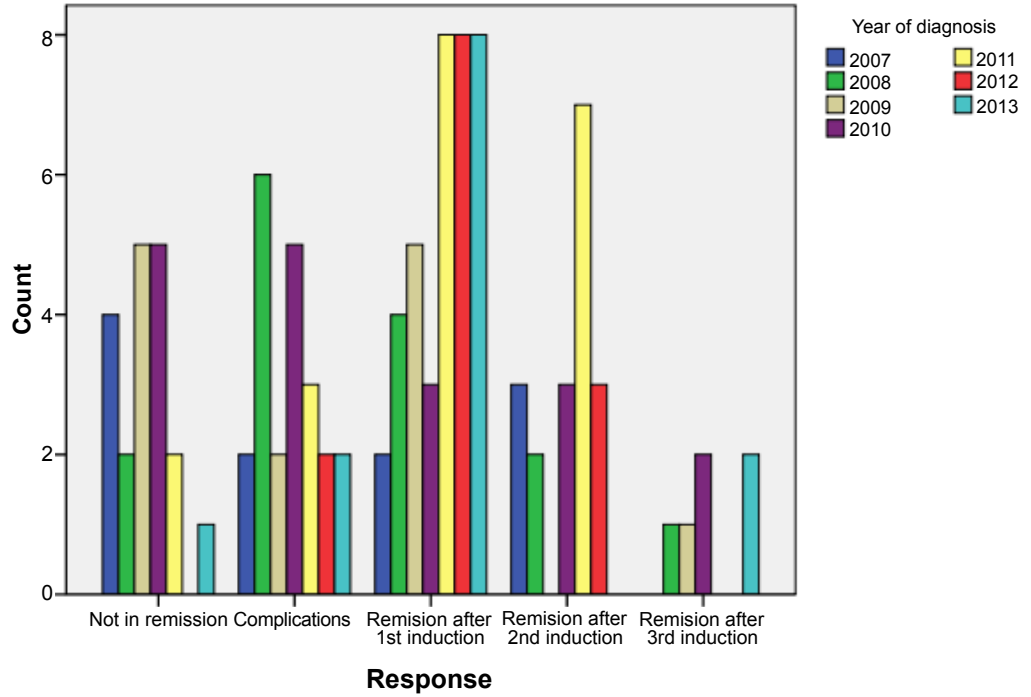

Figure 3: Bar chart of response to low dose Doxorubicin treatment in non-APL acute myeloblastic leukemia patients over years of the study. 


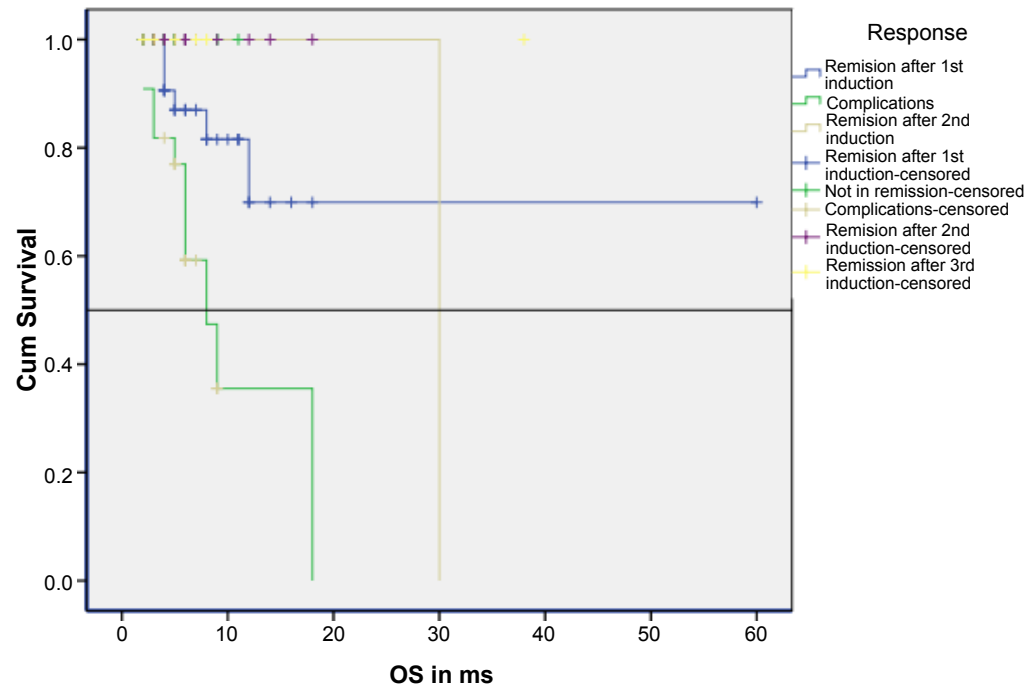

Figure 4: Kaplan-Meier survival analysis for different levels of response to low dose Doxorubicin in the study patients $($ Log Rank $($ Mantel-Cox $)=22.8$, $P$-value=000).

and female patients, respectively. The longest OS and DFS were 60 and $55 \mathrm{~ms}$ for the whole study group. Figure 4 illustrated overall survival of the study patients for the different levels of therapeutic response, longer overall survival was apparent for the group who remit after $1^{\text {st }}$ induction.

\section{Discussion}

This study was conducted to assess the efficacy of low dose Doxorubicin in 3/7 induction regimen for patients with non- APL AML. In our center, Doxorubicin is the preferred anthracycline in induction therapy for AML compared to idarubicin or daunorubicin as it is the cheapest and most available anthracycline. It is available in $20 \mathrm{mg}$ vials, and the used dose was $25 \mathrm{mg} / \mathrm{m}^{2}$ (during the study years), with this dose the toxicity of the regimen is somewhat tolerable. Furthermore the possibility of exceeding the highest cumulative dose $\left(450-550 \mathrm{mg} / \mathrm{m}^{2}\right)$ is rare for those who received recurrent inductions.

AML patients were included in this study after fulfillment of certain inclusion criteria, accordingly descriptive characteristics, concerned with gender, age, etc, of our patients could not be applied to AML patients in our locality.

In this study, induction with low dose Doxorubicin achieved $60.2 \%$ remission rate which was higher than that was achieved by Yates and his co-workers with $30 \mathrm{mg} / \mathrm{m}^{2}$ Doxorubicin. In the meantime this was nearly similar to the remission rate achieved with $30 \mathrm{mg} / \mathrm{m}^{2}$ Daunorubicin in the same study. These differences in response could be explained by the lack of patient selection in Yates study, accordingly the study included patients who were expected to have poor response [18].

In a recent study at the National Cancer Institute, Egypt, $45 \mathrm{mg} / \mathrm{m}^{2}$ Doxorubicin in adult AML patients aged 15-60 years, achieved a CR of $67.1 \%$ [19]. This rate is nearly similar to the CR obtained in the current study. These findings confirmed the findings of Sonneveld et al., who concluded that dosage reduction may reduce toxicity with no concomitant decrease of antileukemic activity of Doxorubicin [20]. On the other hand results of our study reaffirmed the findings of many clinical trials and concluded that there is no advantage of one anthracycline over another [21].
A serious issue in treatment of AML is the development of chemoresistance, this could be in the form of primary resistance or chemoresitant relapse after achievement of CR. Resistance was found to be due to ineffective eradication of chemoresistant leukemic cells [22-24]. In this respect we suggested that our low dose Doxorubicin regimen would allow adding adjunctive treatment such as Valspodar or cladripine to avoid primary resistance or even in relapsed cases [25].

Unlike other studies, age and gender had no significant influence on therapeutic response. This is because the age range of the study patients was an inclusion criterion, thus fragile elderly patients were not included in the study. On the other hand our results supported the findings of Kayser et al., who concluded that de novo AML type is an important good prognostic factor [26-28]. Also, the current study supported other studies that showed an association between TLC, blast $\%$ at diagnosis and the obtained therapeutic responses [29,30].

A considerable proportion of our patients stopped treatment (29.1\%), another group was lost during follow up (14.4\%). These results was higher than other studies [27]. The main explanation of these findings is the background knowledge of Egyptian population about the poor prognosis of AML. Furthermore, most Egyptians consider chemotherapy a fatal treatment modality that worsens patient condition and shortens his life expectancy. This background image about chemotherapeutics is mainly based on the gastrointestinal, dermatological and hematological complications of chemotherapy. Accordingly lowering the dose of Doxorubicin will reduce complications and could improve this image.

Another reason for patients' incompliance is the limited availability of will equipped health centers that capable of dealing with AML patients in Upper Egypt. Accordingly patients have to travel long distances for their follow up visits. Moreover, AML create a burden on patients' families due to higher treatment expenses and lower socioeconomic status of the patients.

On the other hand the death rate of our patients was lower than that in comparable studies [31]. In this study, the mortality rate included early deaths within the first 30 -days and late deaths afterwards. This difference could be explained by the retrospective nature of the study that allowed considering death during hospital admission only. 
Citation: Khaled SAA (2019) Efficacy of Low Dose Doxorubicin Therapy in Patients with Non-APL Acute Myeloblastic Leukemia. J Blood Lymph 9: 253.

Similar to other studies relapse rate in our patients was $10.7 \%$ [31]. However survival analysis of our patients was dependent in many cases on the date of last follow up and not the date of death accordingly estimation of 5-year survival was hard.

\section{Conclusion and Recommendations}

In conclusion results of this study confirmed our assumption that low dose Doxorubicin regimen is an effective, relatively cheaper and more tolerable alternative for induction of remission in young age adults with AML. Moreover the current study provided scientific evidence that recurrent induction with the same regimen in those who did not achieve CR, carries little possibility of future cardiotoxicity. Another advantage of this regimen is the safety to add adjunctive drugs and guard against resistance. However, we still need long term prospective studies to assess efficacy, safety, and advantages of this regimen.

Based on the findings of the current study we recommended low dose Doxorubicin for induction of remission in young age adults with non-APL AML.

\section{Acknowledgements}

We would like to recognize the HOD of Internal Medicine Department for support and help in ethical approval of the study.

\section{Conflict of Interest} study.

The authors declared that there was no conflict of interest concerned with the

\section{References}

1. Döhner H, Weisdorf DJ, Bloomfield CD (2015) Acute Myeloid Leukemia N Engl J Med 373: 1136-1152

2. Bonnet D, Dick JE (1997) Human Acute Myeloid Leukemia is Organized as a Hierarchy that Originates from a Primitive Hemtatopoietic Cell. Nat Med 3: 730-737.

3. Smith M, Barnett M, Bassan R, Gatta G, Tondini C, et al. (2004) Adult acute myeloid leukaemia. Crit Rev Oncol Hematol 50: 197-222.

4. Redaelli A, Lee JM, Stephens JM, Pashos CL (2003) Epidemiology and clinical burden of acute myeloid leukemia. Expert Rev Anticancer Ther 3: 695-710.

5. Tallman MS, Gilliland DG, Rowe JM (2005) Drug therapy for acute myeloid leukemia. Blood 106: 1154-1163.

6. Lee JH, Joo YD, Kim H, Bae SH, Kim MK, et al. (2011) A randomized trial comparing standard versus high dose daunorubicin induction in patients with acute myeloid leukemia. Blood 118: 3832- 41.

7. Gerwitz DA (1999) A critical evaluation of the mechanisms of action proposed for the antitumor effects of the anthracycline antibiotics adriamycin and daunorubicin. Biochem Pharmacol 368: 131-136.

8. Yates J, Glidewell O, Wiernik P, Cooper MR, Steinberg D, et al. (1982) Cytosine arabinoside with daunorubicin or adriamycin for therapy of acute myelocytic leukemia: A CALGB study. Blood 60: 454-462.

9. Lee BD, Sevcikova S, Kogan SC (2006) Dual Treatment with FLT3 inhibitor SU 11657 and doxorubicin increases survival of leukemic mice. Leuk Res 31: $1131-1134$

10. Lipshultz S, Colan SD, Gelber RD, Perez-Atayde AR, Sallan SE, et al. (1991) Late cardiac effects of doxorubicin therapy for acute lymphoblastic leukemia in childhood. N Engl J Med 324: 808-815.

11. Singal P, lliskovic N (1998) Doxorubicin Induced Cardiomyopathy. N Engl J Med 339: 900-905

12. van der Pal HJ, van Dalen EC, van Delden E, van Dijk IW, Kok WE, et al. (2012) High risk of symptomatic cardiac events in childhood cancer survivors. J Clin Oncol 30: 1429-1437.

13. Burnett AK, Russell NH, Hills RK, Kell J, Cavenagh J, et al. (2015) A randomized comparison of daunorubicin $90 \mathrm{mg} / \mathrm{m} 2$ vs $60 \mathrm{mg} / \mathrm{m} 2$ in AML induction: results from the UK NCRI AML17 trial in 1206 patients. Blood 125: 3878-3885.

14. Wiernik PH1, Banks PL, Case DC Jr, Arlin ZA, Periman PO, et al. (1992) Cytarabine plus idarubicin or daunorubicin as induction and consolidation therapy for previously untreated adult patients with acute myeloid leukemia. Blood 79: 313-319.

15. Vogler WR1, Velez-Garcia E, Weiner RS, Flaum MA, Bartolucci AA, et al (1992) A phase III trial comparing idarubicin and daunorubicin in combination with cytarabine in acute myelogenous leukemia: a Southeastern Cancer Study Group study. J Clin Oncol 10: 1103-1111.

16. Cheson BD, Bennett JM, Kopecky KJ, Büchner T, Willman CL, et al. (2003) Revised Recommendations of the International Working Group for Diagnosis Standardization of Response Criteria, Treatment Outcomes, and Reporting Standards for Therapeutic Trials in Acute Myeloid Leukemia. J Clin Oncol 21 4642-4649.

17. Bennett JM, Catovsky D, Daniel MT, Flandrin G, Galton DA, et al. (1985) Proposed revised criteria for the classification of acute myeloid leukemia a report of the french-american-british cooperative group. Ann Intern Med 103 620-625.

18. Hemat Afifi (2017) Doxorubicin versus Idarubicin with overall survival in adult acute myeloid leukemia patients. Health \&Medicine.

19. Sonneveld P, Mulder JA, van Bekkum DW (1981) Cytotoxicity of doxorubicin for normal hematopoietic and acute myeloid leukemia cells of the rat. Cancer Chemother Pharmacol 5: 167-173.

20. Floyd JD, Nguyen DT, Lobins RL, Bashir Q, Doll DC, Perry MC, et al. (2005) Cardiotoxicity of Cancer Therapy. J Clin Oncol 23: 7685-7696.

21. Dohner H, Estey EH, Amadori S, Appelbaum FR, Buchner T, et al. (2010) Diagnosis and management of acute myeloid leukemia in adults: recommendations from an international expert panel, on behalf of the European LeukemiaNet. Blood 115: 453-474.

22. Leith CP, Kopecky, Chen IM, Slovak ML, Head DR, et al. (1997) Frequency and clinical significance of expression of the multidrug resistance proteins MDR1, MRP1 and LRP in acute myeloid leukemia patients less than 65 ys old A Southwest Oncology Group Study. Blood 90: 389 a.

23. Wuchter C, Leonid K, Ruppert V, Schrappe M, Büchner T, et al. (2000) Clinical significance of P-glycoprotein expression and function for response to induction chemotherapy, relapse rate and overall survival in acute leukemia. Haematologica 85: 711-721.

24. Gruber A, Bjorkholm M, Brinch L, Evensen S, Gustavsson B, et al. (2003) A phase I/II study of the MDR modulator Valspodar (PSC 833) combined with daunorubicin and cytarabine in patients with relapsed and primary refractory acute myeloid leukemia. Leuk Res 27: 323-328

25. Buchner T, Berdel WE, Haferlach C, Haferlach T, Schnittger S, et al. (2009) Age-related risk profile and chemotherapy dose response in acute myeloid leukemia: a study by the German Acute Myeloid Leukemia Cooperative Group. J Clin Oncol 27: 61-69.

26. Kantarjian HM, Thomas XG, Dmoszynska A, Wierzbowska A, Mazur G, et al. (2012) Multicenter, randomized, open-label, phase III trial of decitabine versus patient choice, with physician advice, of either supportive care or low-dose cytarabine for the treatment of older patients with newly diagnosed acute myeloid leukemia. J Clin Oncol 30: 2670-2677.

27. Kayser S, Dohner K, Krauter J, Kohne CH, Horst HA, et al. (2011) The impact of therapy-related acute myeloid leukemia (AML) on outcome in 2853 adult patients with newly diagnosed AML. Blood 117: 2137-2145.

28. Fenaux P, Mufti GJ, Hellstrom-Lindberg E, Santini V, Gattermann N, et al. (2010) Azacitidine prolongs overall survival compared with conventional care regimens in elderly patients with low bone marrow blast count acute myeloid leukemia. J Clin Oncol 28: 562-569.

29. Keating MJ, Smith TL, Ghan EA, McCredie KB, Bodey GP, et al. (1980) Factors related to lenghth of complete remission in adult acute leukemia. Cancer 45 2017-2029.

30. Lima AS, de Mello MR, Fernades E, Bezerra MF, Olieveira MM, et al. (2015) Clinical outcomes of patients with acute myeloid leukemia: evaluation of genetic and molecular findings in a real-life setting. Blood 127: 1863-1865.

31. Estey EH (2000) Treatment of relapsed and refractory acute myelogenous leukemia. Leukemia 14: 476-479. 